\title{
Aerosol Lidar Intercomparison in the Framework of SPALINET-The Spanish Lidar Network: Methodology and Results
}

\author{
Michaël Sicard, Francisco Molero, Juan Luis Guerrero-Rascado, Roberto Pedrós, Francisco Javier Expósito, \\ Carmen Córdoba-Jabonero, José Miguel Bolarín, Adolfo Comerón, Member, IEEE, Francesc Rocadenbosch, \\ Manuel Pujadas, Lucas Alados-Arboledas, Jose Antonio Martínez-Lozano, Juan Pedro Díaz, \\ Manuel Gil, Alberto Requena, Francisco Navas-Guzmán, and José Maria Moreno
}

\begin{abstract}
A group of eight Spanish lidars was formed in order to extend the European Aerosol Research Lidar NetworkAdvanced Sustainable Observation System (EARLINET-ASOS) project. This study presents intercomparisons at the hardware and software levels. Results of the system intercomparisons are based on range-square-corrected signals in cases where the lidars viewed the same atmospheres. Comparisons were also made for aerosol
\end{abstract}

Manuscript received July 25, 2008; revised December 10, 2008 and February 23, 2009. First published July 7, 2009; current version published September 29, 2009. This work was supported in part by the European Union and FEDER funds under the EARLINET-ASOS Project [EU Coordination Action Contract 025991 (RICA)] and the project entitled "Technology Development Programme Toward a European Extremely Large Telescope" [ELT Design Study, EU Specific Support Action, Contract 011863 (RIDS)], by the European Space Agency under Project 21487/08/NL/HE, and by the Spanish Ministry of Science and Innovation (MICINN) and FEDER funds under Project TEC2006-07850/TCM and the Complementary Actions CGL2008-01330-E, CGL2007-28871-E/CLI, CGL2006-26149-E/CLI, and CGL2006-27108-E/ CLI. The synthetic profiles used for the intercomparison at the software level were kindly provided by Christine Böckmann from the Institute of Mathematics of the University of Potsdam.

M. Sicard and F. Rocadenbosch are with the Remote Sensing Laboratory (RSLab), Department of Signal Theory and Communications, and the Institut d'Estudis Espacials de Catalunya, Centre de Recerca de l'Aeronàutica i de l'Espai, Universitat Politènica de Catalunya (UPC), 08034 Barcelona, Spain (e-mail: msicard@tsc.upc.edu; roca@tsc.upc.edu).

F. Molero and M. Pujadas are with the Centro de Investigaciones Energéticas, Medioambientales y Tecnológicas (CIEMAT), 28040 Madrid, Spain (e-mail: f.molero@ciemat.es; manuel.pujadas@ciemat.es).

J. L. Guerrero-Rascado, L. Alados-Arboledas, and F. Navas-Guzmán are with the Atmospheric Physics Group, Centro Andaluz de Medio Ambiente (CEAMA), University of Granada, 18071 Granada, Spain (e-mail: rascado@ugr.es; alados@ugr.es; fguzman@ugr.es).

R. Pedrós and J. A. Martínez-Lozano are with the Department of Thermodynamics, Facultat de Fisica, Universitat de Valencia, 46100 Valencia, Spain (e-mail: roberto.pedros@uv.es; jose.a.martinez@uv.es).

F. J. Expósito and J. P. Díaz are with the Department of Fundamental Physics, University of La Laguna, 38207 La Laguna, Spain (e-mail: fexposit@ull.es; jpdiaz@ull.es).

C. Córdoba-Jabonero and M. Gil are with the Department Earth Observation, Remote Sensing and Atmosphere, Instituto Nacional de Técnica Aeroespacial (INTA), 28850 Torrejón de Ardoz, Spain (e-mail: cordobajc@inta.es; gilm@inta.es).

J. M. Bolarín and A. Requena are with the Department of Chemistry-Physics, Facultad de Química, Universidad de Murcia, 30100 Murcia, Spain (e-mail: jbolarin@um.es; rqna@um.es).

A. Comerón is with the RSLab, Department of Signal Theory and Communications, UPC, 08034 Barcelona, Spain (e-mail: comeron@ @tsc.upc.edu).

J. M. Moreno is with the Department of Chemistry and Environment Engineering, Universidad Politécnica de Cartagena, 30202 Cartagena, Spain (e-mail: sele.moreno@upct.es).

Color versions of one or more of the figures in this paper are available online at http://ieeexplore.ieee.org.

Digital Object Identifier 10.1109/TGRS.2009.2021525 backscatter coefficients at $1064 \mathrm{~nm}(2$ systems) and $532 \mathrm{~nm}$ (all systems), and for extinction coefficients at $532 \mathrm{~nm}$ ( 2 systems). In total, three field campaigns were carried out between 2006 and 2007. Comparisons were limited to the highest layer found before the free troposphere, i.e., either the atmospheric boundary layer or the aerosol layer just above it. Some groups did not pass the quality assurance criterion on the first attempt. Following modification and improvement to these systems, all systems met the quality criterion. The backscatter algorithm intercomparison consisted of processing lidar signal profiles simulated for two types of atmospheric conditions. Three stages with increasing knowledge of the input parameters were considered. The results showed that all algorithms work well when all inputs are known. They also showed the necessity to perform, when possible, additional measurements to attain better estimation of the lidar ratio, which is the most critical unknown in the elastic lidar inversion.

Index Terms-Aerosols, backscatter algorithm intercomparison, lidar, network, system intercomparison.

\section{INTRODUCTION}

$\mathbf{A}$ CTIVE instruments such as lidars provide detailed information on the aerosol spatial distribution throughout the observation line of sight at daytime and nighttime. Satellitebased lidars, such as the Geosciences Laser Altimeter System onboard the Ice, Cloud and land Elevation Satellite (ICESAT, 2003) [1] and the Cloud-Aerosol Lidar with Orthogonal Polarization (CALIOP) onboard the Cloud-Aerosol Lidar and Infrared Pathfinder Satellite Observation (CALIPSO, 2006) [2], [3], offer global coverage but with revisit times on the order of ten days. Coordinated terrestrial lidar networks simultaneously offer the temporal and vertical high resolution of each individual instrument, combined with the spatial sampling within the network area: They are a suitable tool for performing groundtruth observations and can follow the temporal evolution of the aerosol distribution over an extensive region.

The European Aerosol Research Lidar Network (EARLINET) [4] was created in May 2000 within a project from the Fifth Framework Programme (FP) of the European Union (EU) to establish an aerosol climatology. The number of lidar stations involved in the network was 19 in 2000 and has risen to 25 today. Since March 2006, it is endorsed by the coordinated action EARLINET-Advanced Sustainable Observation System (EARLINET-ASOS) [5] from the Sixth FP of the EU. The main objective of EARLINET-ASOS is to 
improve the EARLINET infrastructure, resulting in a better spatial and temporal coverage of the observations, continuous end-to-end quality control for each observation system, and rapid availability of standardized data products.

The lidars from EARLINET present a great variety of characteristics [6], and one of the specific objectives of EARLINETASOS is to optimize instruments and define advanced lidars able to operate unattended and to acquire enough data to retrieve range-resolved aerosol optical and microphysical parameters. To concentrate their efforts on this specific objective, the Spanish lidar community created a Spanish Lidar Network (SPALINET). The first goal of this network is to perform an intercomparison of instruments at the hardware and software levels, and check the results against EARLINET quality control tolerances.

\section{SPALINET}

The SPALINET (see www.lidar.es/spalinet) network is an initiative from the three Spanish groups belonging to EARLINET-ASOS. It officially started on January 1, 2007, and is financially supported by the Spanish Ministry of Science and Innovation. A total of eight research centers and universities distributed in the Iberian Peninsula and the Canary Islands are participating. (The first three letters in the parentheses pertain to the abbreviation of the name of the lidar station.)

1) Universidad Politécnica de Cataluña, Barcelona: The instrument is situated in Barcelona (BAR, $41.39 \mathrm{~N}, 2.11 \mathrm{E}$, $115 \mathrm{~m}$ asl).

2) Centro de Investigaciones Energéticas Medioambientales y Tecnológicas, Madrid. The instrument is situated in Madrid (MAD, 40.46 N, 3.72 W, $665 \mathrm{~m}$ asl).

3) Universidad de Granada, Granada. The instrument is situated in Granada (GRA, 37.16 N, 3.58 W, $680 \mathrm{~m}$ asl).

4) Universidad de La Laguna, La Laguna. The instrument is situated in La Laguna (LLA, $28.48 \mathrm{~N}, 16.32 \mathrm{~W}$, $550 \mathrm{~m}$ asl).

5) Instituto Nacional de Técnica Aerospacial, Torrejón de Ardoz. The instrument is situated in Santa Cruz de Tenerife (SCT, 28.47 N, 16.23 W, $52 \mathrm{~m}$ asl).

6) Universidad de Valencia, Valencia. The instrument is situated in Valencia (VAL, 39.51 N, $0.42 \mathrm{~W}, 60 \mathrm{~m}$ asl).

7) Universidad de Murcia, Murcia. The instrument is situated in Murcia (MUR, 38.02 N, 1.15 W, $90 \mathrm{~m}$ asl).

8) Universidad Politécnica de Cartagena, Cartagena. The instrument is situated in Cartagena (CAR, $37.37 \mathrm{~N}$, $0.57 \mathrm{~W}, 5 \mathrm{~m}$ asl).

The main characteristics of SPALINET instruments are summarized in Table I, and their geographical distribution is shown in Fig. 1. Three of them are laboratory instruments, and the rest were purchased from specialized companies. All the systems, except Murcia and Cartagena, are regularly measuring aerosol backscatter and/or extinction coefficients. Murcia employs its system mainly for determining the aerosol load when Saharan dust intrusions occur and studying the dust influence on the precipitation of the region. The Cartagena system employs the DIAL technique to measure the concentration of chemical components, such as $\mathrm{SO}_{2}, \mathrm{O}_{3}, \mathrm{NO}_{2}$, and toluene. All the systems are able to measure at or close to the wavelength of $532 \mathrm{~nm}$ (the SCT system measures at $523 \mathrm{~nm}$ ), and half of them can measure at $1064 \mathrm{~nm}$. Three of the systems are able to measure the Raman channel of $\mathrm{N}_{2}$ at the $607 \mathrm{~nm}$.

The network aims to promote the use of lidar instruments and data among the Spanish scientific community. The main goals of the network are given as follows:

1) extend and reinforce the actions of EARLINET-ASOS;

2) form a nucleus for stimulating the Spanish lidar community and promote the participation of new groups for improving the spatial cover of aerosol vertical measurements on the Spanish territory (with a possible extension to Portugal);

3) strengthen the membership and capabilities of SPALINET by voluntary participation in field campaigns in support of international projects dedicated to the study of aerosols and their impact on the global radiative budget.

More specifically, in the first two years of the project, efforts are directed to assuring the quality of instrumental data. This goal will be achieved by performing, during the first year, an intercomparison at the hardware level and, during the second year, an intercomparison of retrieval algorithms using synthetic data for a number of situations of different complexities. The results of the first two years are presented in this paper.

\section{DATA ANALYSIS}

\section{A. Normalized Distance}

Before performing any type of data processing, it is useful to estimate how well the range-square-corrected signals (RSCSs) of two different systems agreed in a given altitude interval. This indicates the similarity of the system responses to the same scene at the hardware-plus-preprocessing level. The signal similarity between two instruments labeled $a$ and $b$ was measured by calculating the normalized distance $d_{a, b}(n, m)$ between their RSCS in a height interval limited by $z_{n}$ and $z_{m}(m>n)$, which is defined by

$$
d_{a, b}(n, m)=\sqrt{1-\sigma_{a, b}(n, m)}
$$

where $\sigma_{a, b}$ is the normalized correlation coefficient

$$
\sigma_{a, b}(n, m)=\frac{\left(\sum_{i=n}^{m} X_{a}\left(z_{i}\right) X_{b}\left(z_{i}\right)\right)^{2}}{\sum_{i=n}^{m} X_{a}^{2}\left(z_{i}\right) \sum_{i=n}^{m} X_{b}^{2}\left(z_{i}\right)}
$$

with $X_{a}\left(z_{i}\right)=z_{i}^{2} P_{a}\left(z_{i}\right)$ and $X_{b}\left(z_{i}\right)=z_{i}^{2} P_{b}\left(z_{i}\right)$ being the RSCSs at altitude $z_{i}$ of the instruments labeled $a$ and $b$, respectively. $P_{a}\left(z_{i}\right)$ and $P_{b}\left(z_{i}\right)$ are the respective received powers from altitude $z_{i}$.

The use of the normalized correlation is necessary in order to avoid biases due to the use of noncalibrated systems. The resulting normalized distance will be $\ll 1$ if, between the two heights $z_{n}$ and $z_{m}$, both systems have very similar RSCSs. In turn, it will be $\sim 1$ if both RSCSs are very different. 
TABLE I

CHARACTERISTICS OF SPALINET LIDARS SYSTEMS. SUPERSCRIPT "a” INDICATES DETECTION OF Both P- AND S-POLARIZED COMPONENTS. SUPERSCRIPT "b" CORRESPONDS TO THE WAVELENGTH OF $523 \mathrm{~nm}$ AND NOT $532 \mathrm{~nm}$. THE BOLD NuMBERS INDICATE THE WAVELENGTHS INTERCOMPARED

\begin{tabular}{|c|c|c|c|c|c|c|c|c|c|}
\hline & & \multicolumn{8}{|c|}{ Lidar station } \\
\hline & Units & $B A R$ & MAD & GRA & $L L A$ & $S C T$ & $V A L$ & MUR & CAR \\
\hline Lidar model & - & laboratory & laboratory & $\begin{array}{l}\text { Raymetrics } \\
\text { LR321-D400 }\end{array}$ & $\begin{array}{l}\text { Eridan } \\
\text { LSA-2c }\end{array}$ & $\begin{array}{l}\text { SES Inc. } \\
\text { MPL-3 }\end{array}$ & $\begin{array}{l}\text { CIMEL Electronique } \\
\text { CAML CE370-2 }\end{array}$ & laboratory & $\begin{array}{l}\text { Elight } \\
\text { UV11 }\end{array}$ \\
\hline Elastic IR 1064 & $\mathrm{~mJ}$ & 160 & - & 110 & 100 & - & - & 1000 & - \\
\hline Elastic VIS 532 & $\mathrm{~mJ}$ & 160 & 100 & $65^{\mathrm{a}}$ & $\mathbf{5 0}$ & $0.01^{b}$ & 0.004 & 500 & - \\
\hline Elastic UV 355 & $\mathrm{~mJ}$ & - & - & 60 & - & - & - & 250 & - \\
\hline Elastic UV 266 & $\mathrm{~mJ}$ & - & - & - & - & - & - & 110 & - \\
\hline Elastic UV 390-399 & $\mathrm{mJ}$ & - & - & - & - & - & - & Yes & Yes \\
\hline Elastic UV 255-290 & $\mathrm{mJ}$ & - & - & - & - & - & - & Yes & Yes \\
\hline Raman VIS 607 & - & Yes & Yes & - & - & - & - & Yes & - \\
\hline Raman UV 387 & - & - & - & Yes & - & - & - & Yes & - \\
\hline Raman UV 407 (WV) & - & - & - & Yes & - & - & - & Yes & - \\
\hline PRF & $\mathrm{Hz}$ & 10 & 20 & 10 & 10 & 2500 & 4600 & 10 & 20 \\
\hline Scanning capability & - & Yes & Yes & No & Yes & Yes & No & Yes & Yes \\
\hline System transportable & - & Yes & Yes & Yes & No & Yes & Yes & No & Yes \\
\hline Full overlap height & $\mathrm{km}$ & $\sim 0.4$ & $\sim 0.4$ & $\sim 0.3$ & $\sim 0.3$ & $\sim 1.5$ & $\sim 1$ & $\sim 2$ & $\sim 0.3$ \\
\hline Maximum range & $\mathrm{km}$ & 50 & 15 & 120 & 10 & 60 & 5 & 50 & 5 \\
\hline
\end{tabular}

\section{B. Aerosol Backscatter}

As all the SPALINET systems have at least one pureelastic backscatter channel, backscatter coefficients were compared in the first instance. The retrieval algorithm used is the Klett-Fernald-Sasano algorithm [7]-[9], in which the effects of the molecules and the aerosols are separately considered. The atmosphere total backscatter coefficient $\beta$ is retrieved as a function of the height $z$ from the values of the RSCS $X(z)$ as (3), shown at the bottom of the next page

where

$$
\begin{aligned}
& \beta_{a}(z) \\
& \beta_{m}(z) \\
& z_{m} \\
& S_{a}(z)=\alpha_{a}(z) / \beta_{a}(z)
\end{aligned}
$$

aerosol backscatter coefficient; molecular (Rayleigh) backscatter coefficient;

range from which the inversion is started;

aerosol lidar ratio given by the ratio between the aerosol ex- tinction coefficient $\alpha_{a}(z)$ and the aerosol backscatter coefficient $\beta_{a}(z)$;

$S_{m}=\alpha_{m} / \beta_{m}=8 \pi / 3$ sr molecular lidar ratio that is given by the ratio between the molecular extinction coefficient $\alpha_{m}$ and the molecular backscatter coefficient $\beta_{m}$ and is independent of the height.

The term $\beta\left(z_{m}\right)$ represents the boundary condition where the total backscatter coefficient is assumed to be known. Here, only the backward solution was considered as the intercomparison dealt only with ground-based systems. The molecular coefficient profiles were calculated using the ground values of temperature and pressure, and standard atmosphere conditions [10]. All the aerosol backscatter coefficients presented in the intercomparison at the hardware level were retrieved with 


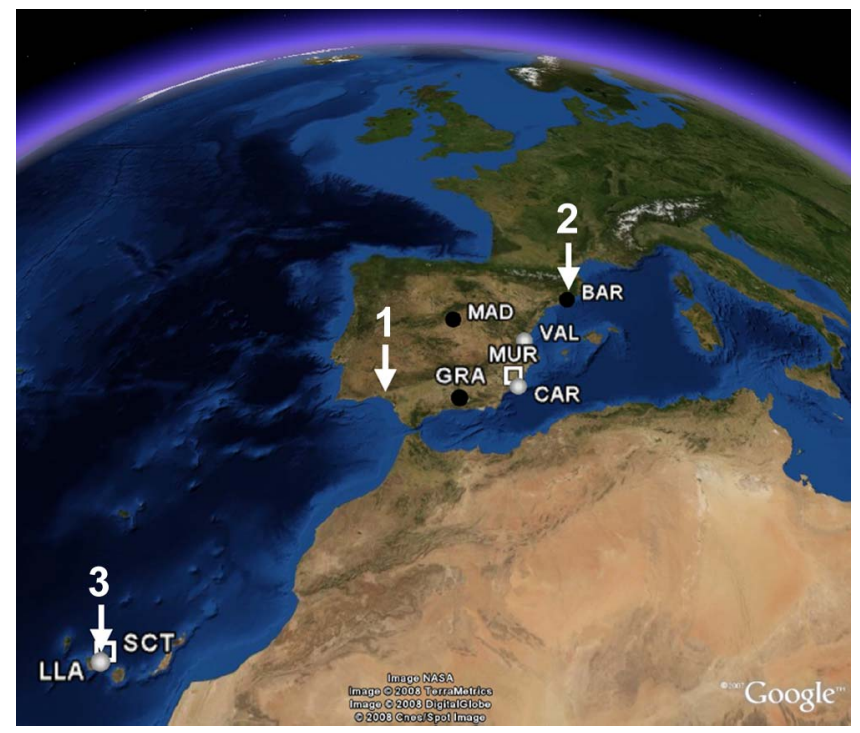

Fig. 1. Geographical distribution of the SPALINET lidar systems. Circles and squares indicate transportable and untransportable systems, respectively. (Black) Systems involved in EARLINET-ASOS. (White) Locations of the three field campaigns, as numbered in Table II.

the Klett-Fernald-Sasano algorithm and assuming a constant aerosol lidar ratio of $30 \mathrm{sr}$. For each pair of profiles inverted, the same boundary condition $\beta\left(z_{m}\right)$ was chosen at the same height $z_{m}$.

\section{Aerosol Extinction}

In one case, the Raman channel of $\lambda_{R}=607 \mathrm{~nm}$, arising from a vibrational-rotational Raman transition of the $\mathrm{N}_{2}$ in the atmosphere under the excitation at $532 \mathrm{~nm}$, was simultaneously measured by two systems. By using data from both Raman and elastic channels, it is possible to overcome the assumption of an a priori unknown lidar ratio [11]. The solution of Ansmann et al. [11] for the aerosol extinction coefficient at laser wavelength $\alpha_{a, \lambda_{0}}$ is repeated here for the reader's convenience, i.e.,

$$
\begin{aligned}
\alpha_{a, \lambda_{0}}(z) & =\frac{1}{1+\left(\frac{\lambda_{0}}{\lambda_{R}}\right)^{k}} \\
& \cdot\left\{\frac{d}{d z}\left[\ln \frac{N_{R}(z)}{X_{\lambda_{R}}(z)}\right]-\alpha_{m, \lambda_{0}}(z)-\alpha_{m, \lambda_{R}}(z)\right\}
\end{aligned}
$$

where $N_{R}(z)$ is the atmospheric nitrogen molecule number density, and $\alpha_{m, \lambda_{0}}$ and $\alpha_{m, \lambda_{R}}$ are the molecular extinctions for the laser and the Raman wavelengths, respectively.

The backscatter coefficient can also be derived from the expression of $\alpha_{a, \lambda_{0}}$ without assuming an a priori lidar ratio but by choosing a boundary condition $\beta\left(z_{m}\right)$ to eliminate the system constant.

\section{INTERCOMPARISON FIELD CAMPAIGNS}

The intercomparison campaigns had two main objectives: 1) identify the hardware problems and limitations of each system and 2) identify the limitations of the preprocessing software used by each group. Three campaigns were carried out in the following places:

1) El Arenosillo $(37.10 \mathrm{~N}, 6.70 \mathrm{~W}, 17 \mathrm{~m}$ asl) in the southwest of peninsular Spain during June 28, 2006July 2, 2006 in the context of the DAMOCLES field campaign [13];

2) Barcelona (41.39 N, 2.11 E, $115 \mathrm{~m}$ asl) during February 6, 2007-February 8, 2007;

3) La Laguna (28.48 N, $16.32 \mathrm{~W}, 550 \mathrm{~m}$ asl) in the Canary Island of Tenerife during June 24, 2007-June 28, 2007.

They are summarized in Table II, and the sites where they took place are shown in Fig. 1. A total of six systems have been intercompared. The Valencia system, which was present in Campaign 1, had to repeat the experiment in Campaign 2. In the first campaign, technical problems that are mostly related to the alignment of the emission and the reception optics made the measurements useless. The Cartagena system also deployed in Campaign 1 could not perform any measurements because of a software problem. The third campaign took place in La Laguna, because the system from the University of La Laguna is not transportable. Originally, the campaigns lasted five days. In Campaign 2, the first two days of measurement were very fruitful, and as the weather forecasts were bad for the rest of the week, the measurements were stopped around midday on the third day.

The fourth intercomparison campaign took place in Murcia during May 26, 2008-May 30, 2008 in order to compare the last two systems. Unfortunately, the Cartagena system was not operational because of a laser problem. The Murcia system, in spite of the relatively strong power it can emit, was unable to deliver invertible signals. The signal-to-noise ratios were indeed too low because of the slowness of the acquisition system, a gated integrator, which acquires one point of the profile per pulse.

All three field campaigns were carried out in coastal regions where a sea-breeze regime usually settles during daytime. The atmospheric boundary layer (ABL) was usually not higher than $1.5 \mathrm{~km}$. In Campaigns 2 and 3, aerosol layers were detected above the ABL up to $3 \mathrm{~km}$ but not decoupled from it. On one day in Campaign 3 (June 25, 2007), an aerosol layer was detected in the free troposphere decoupled from the ABL.

$$
\begin{aligned}
\beta(z) & =\beta_{a}(z)+\beta_{m}(z) \\
& =\frac{\beta\left(z_{m}\right) X(z) \exp \left\{2 \int_{z}^{z_{m}}\left[S_{a}(u)-S_{m}\right] \beta_{m}(u) d u\right\}}{X\left(R_{m}\right)+2 \beta\left(z_{m}\right) \int_{z}^{z_{m}} S_{a}(u) X(u) \exp \left\{2 \int_{u}^{z_{m}}\left[S_{a}(v)-S_{R}\right] \beta_{m}(v) d v\right\} d u}
\end{aligned}
$$


TABLE II

Place and Dates of the Field Campaigns Carried Out, as Well as THE Compared Quantities Besides the Normalized Distance

\begin{tabular}{|c|c|c|c|c|c|c|c|}
\hline & & \multicolumn{6}{|c|}{ Lidar station } \\
\hline Campaign \# & $\begin{array}{l}\text { Campaign place } \\
\text { and date }\end{array}$ & BAR & MAD & GRA & VAL & LLA & SCT \\
\hline 1 & $\begin{array}{l}\text { El Arenosillo } \\
28 / 6-2 / 7 / 2006\end{array}$ & $\begin{array}{l}\text { Yes } \\
-\end{array}$ & $\begin{array}{l}\text { Yes } \\
\beta_{\mathrm{a}, 532, \alpha_{\mathrm{a}, 532}}\end{array}$ & $\begin{array}{l}\text { Yes } \\
\beta_{\mathrm{a}, 532,} \beta_{\mathrm{a}, 1064}\end{array}$ & $\begin{array}{l}\text { Yes } \\
-\end{array}$ & & \\
\hline 2 & $\begin{array}{l}\text { Barcelona } \\
6-8 / 2 / 2007\end{array}$ & $\begin{array}{l}\text { Yes } \\
-\end{array}$ & & & $\begin{array}{l}\text { Yes } \\
\beta_{\mathrm{a}, 532}\end{array}$ & & \\
\hline 3 & $\begin{array}{l}\text { La Laguna } \\
24-28 / 6 / 2007\end{array}$ & $\begin{array}{l}\text { Yes } \\
-\end{array}$ & & & & $\begin{array}{l}\text { Yes } \\
\beta_{\mathrm{a}, 532}\end{array}$ & $\begin{array}{l}\text { Yes } \\
\beta_{\mathrm{a}, 532}\end{array}$ \\
\hline
\end{tabular}

TABLE III

Maximum Allowed Absolute and Relative Deviations for the Compared AEROSOL BACKSCATTER AND EXTINCTION COEFFICIENTS

\begin{tabular}{|l|l|l|l|}
\hline Quantity & Mean deviation & Standard deviation & $\begin{array}{l}\text { Minimum height } \\
\text { interval }(\mathrm{m})\end{array}$ \\
\hline Aerosol backscatter at $532 \mathrm{~nm}$ & $0.5 \times 10^{-6} \mathrm{~m}^{-1} \cdot \mathrm{sr}^{-1} / 20 \%$ & $0.5 \times 10^{-6} \mathrm{~m}^{-1} \cdot \mathrm{sr}^{-1} / 25 \%$ & 2000 \\
\hline Aerosol backscatter at $1064 \mathrm{~nm}$ & $0.5 \times 10^{-6} \mathrm{~m}^{-1} \cdot \mathrm{sr}^{-1} / 30 \%$ & $0.5 \times 10^{-6} \mathrm{~m}^{-1} \cdot \mathrm{sr}^{-1} / 30 \%$ & 2000 \\
\hline Aerosol extinction at $532 \mathrm{~nm}$ & $0.5 \times 10^{-4} \mathrm{~m}^{-1} / 20 \%$ & $1.0 \times 10^{-4} \mathrm{~m}^{-1} / 25 \%$ & 1000 \\
\hline
\end{tabular}

\section{A. Objectives and Methodology of the Intercomparisons}

The first objective of the field campaigns was to compare in situ the range-square-corrected profiles from different instruments pointing at the same atmospheric target to evidence differences in the acquisition and preprocessing. In all the campaigns, the systems were never located further than $20 \mathrm{~m}$ apart from each other. This task led to many interactions between all the participants and helped them to adjust their system in both hardware and software aspects [12]. Most of the problems encountered during the field campaigns are described in Section V.

The second objective of the campaigns was to quantitatively compare the backscatter (pure-elastic backscatter lidar) and extinction (Raman lidar) coefficients retrieved by the same inversion algorithm. The comparisons were made against the Barcelona system, which was regarded as assured quality since it passed the EARLINET instrument intercomparison exercise in 2001 [6]. When a value of sun-photometer aerosol optical thickness (AOT) [14] was available, the lidar-derived AOT was compared with it in order to check the coherency of the magnitudes found by the lidars.

Diurnal cycle measurements were performed from 0800 to 2000 Coordinated Universal Time (UTC) at the maximum number of elastic wavelengths possible with a 1-min time resolution. By default, the deliverable profiles had to be integrated over $10 \mathrm{~min}$. Since the Valencia system uses a low-energy laser, the comparison of that system was made by integrating the profiles over $30 \mathrm{~min}$. All the groups with Raman channels also performed night-time measurements starting at 2130 UTC with a 1-min time resolution. The deliverable profiles were integrated over $120 \mathrm{~min}$. All systems performed the measurements pointing at zenith and delivered the profiles with a spatial resolution of $15 \mathrm{~m}$ (except the Instituto Nacional de Técnica Aeroespacial system, which has a resolution of 30 or $75 \mathrm{~m}$ ).

\section{B. Compared Quantities and Quality Criteria}

Color maps of the normalized distance were plotted to have a first hint on how well two instruments compared in the ABL and to have an idea of the maximum height where the agreement was good. A total of three optical coefficients were compared (see Table II), i.e., the aerosol backscatter coefficients at 532 and $1064 \mathrm{~nm}$, and the aerosol extinction coefficient at $532 \mathrm{~nm}$.

The conditions of the inversion to retrieve the backscatter and extinction coefficients were given in Sections III-B and C, respectively. The extinction coefficient was retrieved in only one case.

The quality criteria used for the optical coefficients are those described by Matthias et al. [6], which were derived from former experiments performed by the German lidar network back in 1998. The backscatter and extinction coefficients were compared in terms of the absolute and relative mean deviations and in terms of the absolute and relative standard deviations 
TABLE IV

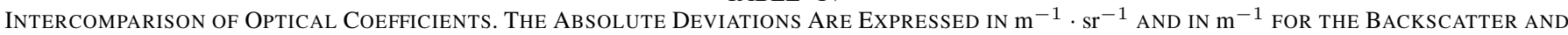
Extinction, Respectively. The AOT Was Measured by Sun-Photometers. The Asterisks in the "Date and Time" Column IndiCATE The Case Shown in Fig. 2. The Maximum Allowed Deviations Are Shown on the Lines Above Each Set of Comparisons

\begin{tabular}{|c|c|c|c|c|c|c|}
\hline & $\begin{array}{l}\text { Date and time } \\
\text { (UTC) }\end{array}$ & $\begin{array}{l}\text { Wavelength } \\
(\mathrm{nm})\end{array}$ & $\begin{array}{l}\text { Mean deviation } \\
\left(\mathrm{x} 10^{-6} / \%\right)\end{array}$ & $\begin{array}{l}\text { Standard deviation } \\
\left(\mathrm{x} 10^{-6} / \%\right)\end{array}$ & $\begin{array}{l}\text { Height interval } \\
\text { (m) }\end{array}$ & AOT \\
\hline $\begin{array}{l}\text { BACKSCATTER } \\
\text { at } 1064 \mathrm{~nm}\end{array}$ & & & $<0.50 / 30.0$ & $<0.50 / 30.0$ & & \\
\hline \multirow{3}{*}{ GRA-BAR } & $28 / 6 / 2006,1856-1906^{*}$ & 1064 & $0.02 / 1.9$ & $0.15 / 25.5$ & $500-1600$ & 0.06 \\
\hline & $29 / 6 / 2006,0847-0857$ & 1064 & $0.13 / 17.5$ & $0.22 / 29.5$ & $500-1800$ & 0.06 \\
\hline & $29 / 6 / 2006,1042-1052$ & 1064 & $0.10 / 13.1$ & $0.21 / 26.9$ & $500-1700$ & 0.06 \\
\hline $\begin{array}{l}\text { BACKSCATTER } \\
\text { at } 532 \mathrm{~nm}\end{array}$ & & & $<0.50 / 20.0$ & $<0.50 / 25.0$ & & \\
\hline \multirow{3}{*}{ GRA-BAR } & $28 / 6 / 2006,0835-0845$ & 532 & $0.14 / 2.9$ & $0.69 / 14.5$ & $500-2000$ & 0.32 \\
\hline & $28 / 6 / 2006,1623-1633^{*}$ & 532 & $0.26 / 11.4$ & $0.42 / 18.3$ & $500-1600$ & 0.17 \\
\hline & $28 / 6 / 2006,1856-1906$ & 532 & $0.04 / 2.0$ & $0.33 / 19.8$ & $500-1700$ & 0.14 \\
\hline \multirow{3}{*}{ MAD-BAR } & $28 / 6 / 2006,1448-1458^{*}$ & 532 & $0.22 / 8.7$ & $0.26 / 10.3$ & $500-2000$ & 0.21 \\
\hline & 29/6/2006, 0847-0857 & 532 & $0.21 / 12.4$ & $0.37 / 22.1$ & $500-1800$ & 0.15 \\
\hline & $29 / 6 / 2006,1042-1052$ & 532 & $0.04 / 1.9$ & $0.47 / 24.0$ & $500-1700$ & 0.17 \\
\hline \multirow{3}{*}{ VAL-BAR } & $6 / 2 / 2007,1514-1544^{*}$ & 532 & $0.26 / 13.8$ & $0.33 / 17.7$ & $800-1800$ & 0.33 \\
\hline & $7 / 2 / 2007,0852-0922$ & 532 & $0.10 / 28.2$ & $0.13 / 36.3$ & $800-1800$ & - \\
\hline & $7 / 2 / 2007,1215-1245$ & 532 & $0.23 / 20.8$ & $0.25 / 22.9$ & $800-1800$ & 0.11 \\
\hline \multirow{3}{*}{ LLA-BAR } & $24 / 6 / 2007,1940-1950$ & 532 & $0.31 / 45.2$ & $0.38 / 55.4$ & $500-2400$ & - \\
\hline & $26 / 6 / 2007,1520-1530$ & 532 & $0.09 / 15.0$ & $0.20 / 36.2$ & $500-2500$ & 0.04 \\
\hline & $26 / 6 / 2007,1605-1615^{*}$ & 532 & $0.08 / 14.0$ & $0.10 / 18.6$ & $500-2500$ & 0.04 \\
\hline \multirow{3}{*}{ SCT-BAR } & 24/6/2007, 0859-0909 & 523 & $0.02 / 2.2$ & $0.17 / 19.6$ & $500-2800$ & 0.1 \\
\hline & $24 / 6 / 2007,1645-1655$ & 523 & $0.11 / 16.1$ & $0.17 / 25.8$ & $500-3200$ & 0.08 \\
\hline & $26 / 6 / 2007,1605-1615^{*}$ & 523 & $0.11 / 20.8$ & $0.14 / 26.5$ & $500-2500$ & 0.04 \\
\hline $\begin{array}{l}\text { EXTINCTION } \\
\text { at } 532 \mathrm{~nm}\end{array}$ & & & $<50 / 20.0$ & $<100 / 25.0$ & & \\
\hline MAD-BAR & $28 / 6 / 2006,2101-2301$ & 532 & $48 / 47.6$ & $60 / 59.6$ & $900-2500$ & - \\
\hline
\end{tabular}

of inverted profiles between two heights $h_{\min }$ and $h_{\max }$ where aerosols were present. $h_{\min }$ was selected as the lowest height where both systems intercompared had reached full overlap, and $h_{\max }$ was selected as the top of the aerosol layer just before the free troposphere. For the reader's convenience, the expression of the four quantities compared is repeated. If we denote the difference between two quantities $m_{1}$ and $m_{2}$ (which could represent either aerosol backscatter or extinction coefficients) at a given height as $\Delta m$, the mean deviation between two heights $z_{i}$ and $z_{j}$ is defined as

$$
\overline{\Delta m}=\frac{\sum_{u=i}^{j} \Delta m}{n}
$$

where $n$ is the number of points between $z_{i}$ and $z_{j}$. If we denote the mean value of quantity $m$ (i.e., the quantity $m_{1}$ or $m_{2}$ taken 

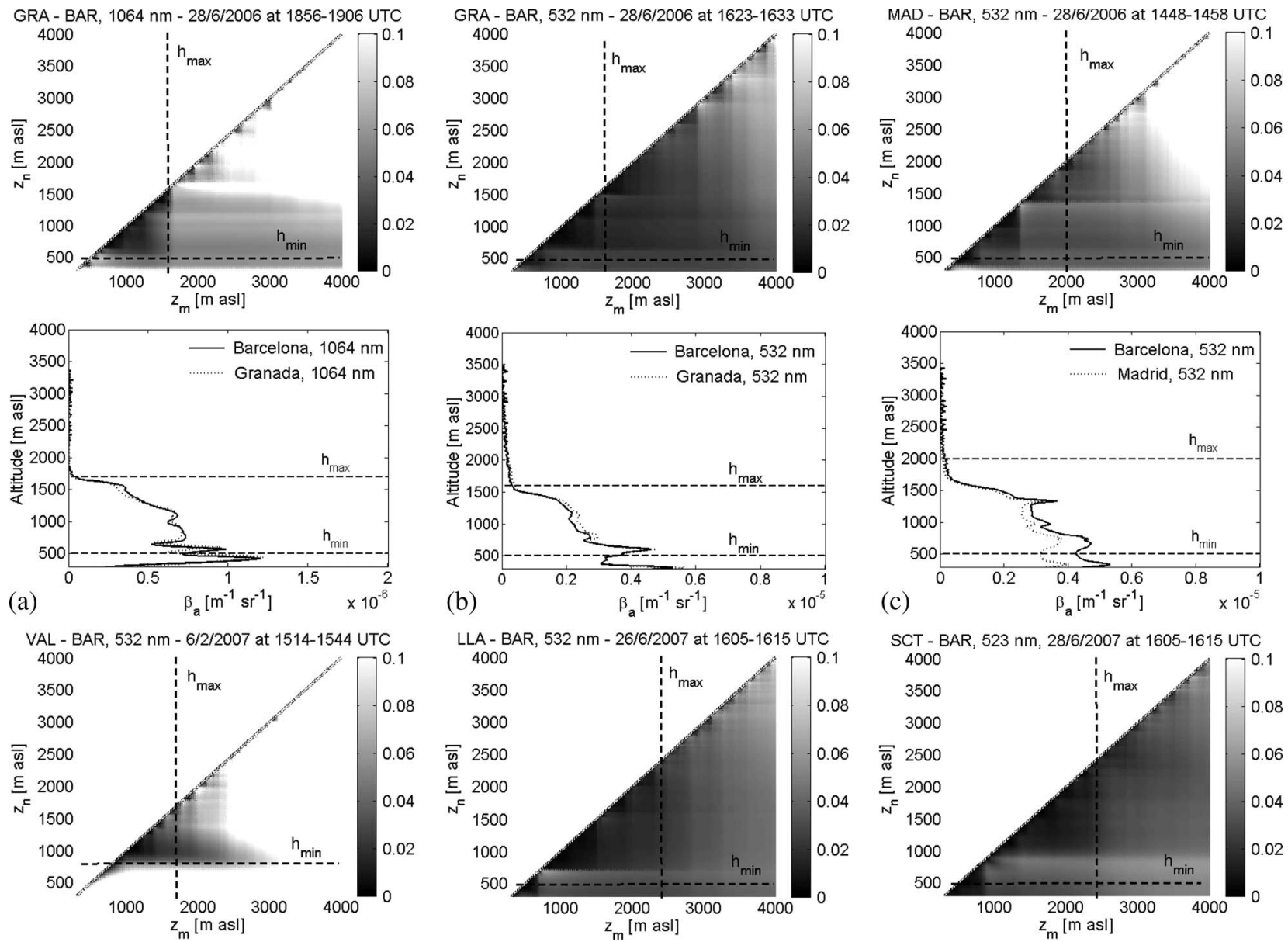

SCT - BAR, $523 \mathrm{~nm}, 28 / 6 / 2007$ at 1605-1615 UTC
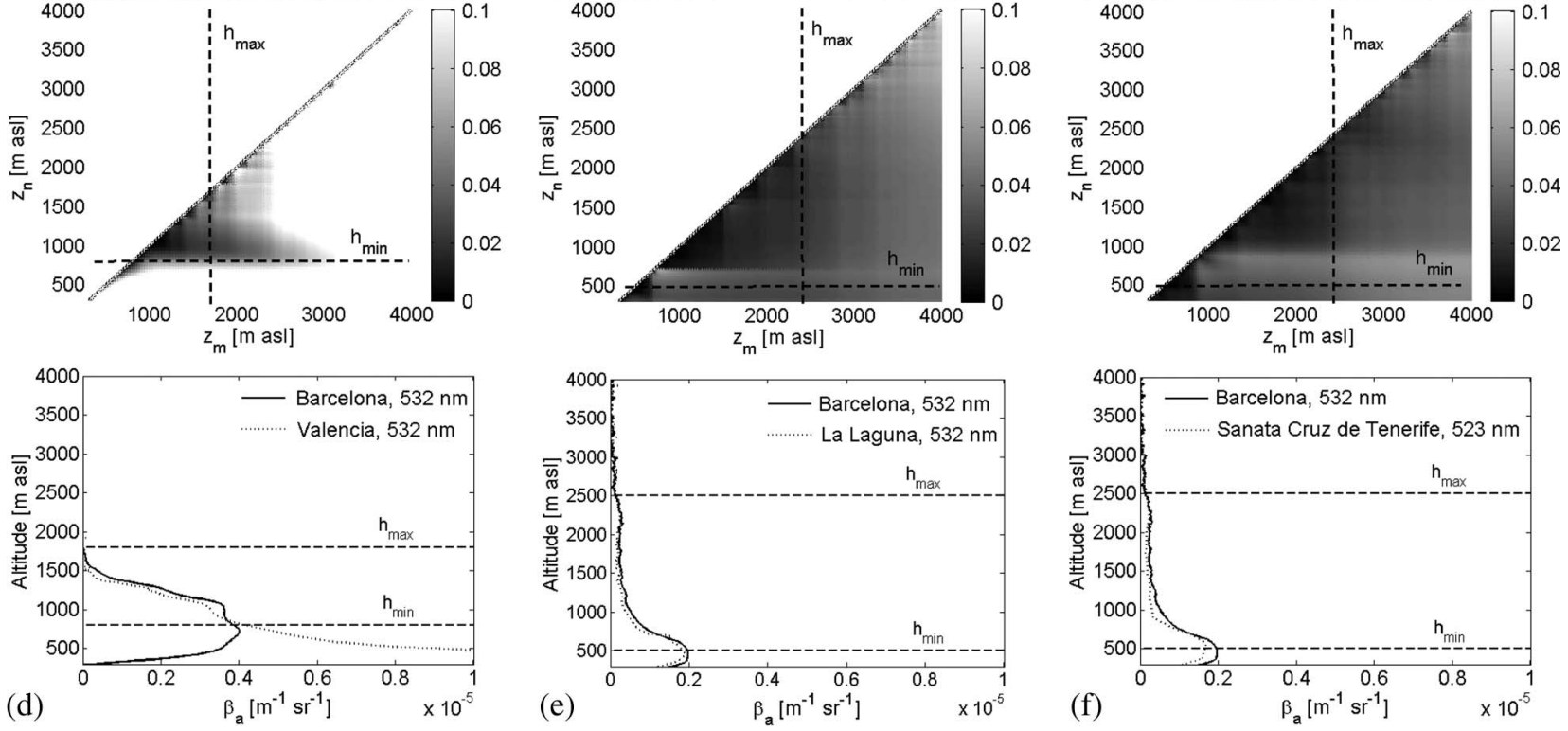

Fig. 2. (Top) Map of the normalized distance $\left(d_{a, b}(n, m)\right)$ and (bottom) intercomparison of the aerosol backscatter profiles between (a) Granada and Barcelona (1064 nm), (b) Granada and Barcelona (532 nm), (c) Madrid and Barcelona (532 nm), (d) Valencia and Barcelona (532 nm), (e) SCT and Barcelona (532 nm), and (f) La Laguna and Barcelona $(532 \mathrm{~nm})$. The minimum and maximum heights used to calculate the mean and standard deviations are indicated by dashed lines.

as reference) between $z_{i}$ and $z_{j}$ as $\bar{m}$, then the relative mean and deviation (in percent) is

$$
\overline{\Delta m}_{\mathrm{rel}}=100 \times \frac{\overline{\Delta m}}{\bar{m}} .
$$

The standard deviation and the relative value of the standard deviation (in percent) are calculated as

$$
\delta m=\left[\frac{\sum_{u=i}^{j}(\Delta m)^{2}}{n-1}\right]^{1 / 2}
$$

$$
\delta m_{\mathrm{rel}}=100 \times \frac{\delta m}{\bar{m}}
$$

respectively.

The intercomparison between two instruments was regarded as successful if either the absolute or the relative values of both the mean and standard deviations stayed below the maximum allowed values fixed by Matthias et al. [6]. Those values are given in Table III, as well as the minimum height intervals (also fixed in the same reference) over which the deviations had to be calculated.

As earlier said, in almost all cases, the aerosol structure was limited to an ABL and a coupled layer on top of it. In those conditions, to guarantee that all systems could actually detect 


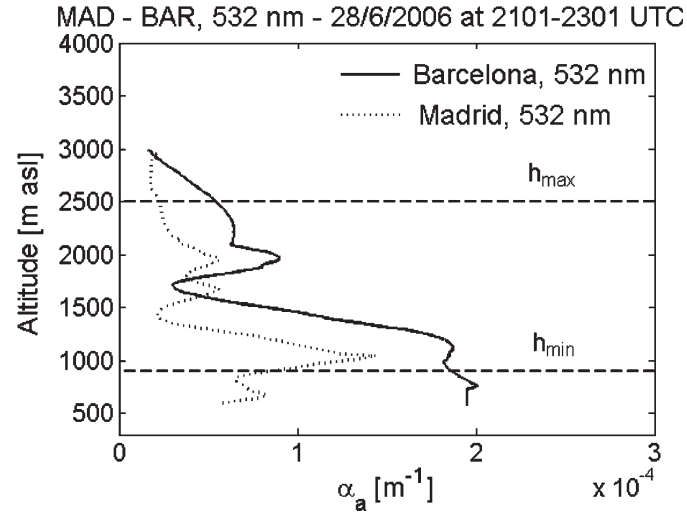

Fig. 3. Intercomparison of the aerosol extinction profiles between Madrid and Barcelona at $532 \mathrm{~nm}$. The minimum and maximum heights used to calculate the mean and standard deviations are indicated by dashed lines.

aerosols within the ABL where the highest aerosol load can be found, minimum values were fixed [6].

1) $\beta_{a}>\beta_{a, \min }=2 \times 10^{-6} \mathrm{~m}^{-1} \cdot \mathrm{sr}^{-1}$ at $532 \mathrm{~nm}$.

2) $\beta_{a}>\beta_{a, \min }=1 \times 10^{-6} \mathrm{~m}^{-1} \cdot \mathrm{sr}^{-1}$ at $1064 \mathrm{~nm}$.

3) $\alpha_{a}>\alpha_{a, \min }=1 \times 10^{-4} \mathrm{~m}^{-1}$ at $532 \mathrm{~nm}$.

\section{SYSTEM INTERCOMPARISON: RESULTS}

The field campaigns showed the importance of the preprocessing that each group applies to its data. In approximately half of the cases, the first profiles provided could not be intercompared, because the system was not correctly set up for the measurement (detector saturation, overlap factor incorrectly adjusted, electronic interferences, etc.) or the preprocessing was wrong (incorrect background calculation, inappropriate use of smoothing techniques, etc.). In all these cases, the measurement and/or preprocessing was repeated until the intercomparison went well.

A total of 131 profiles were inverted, from which 112 fulfilled the condition on the aerosol load on $\beta_{a}>\beta_{a \text {,min }}$ or $\alpha_{a}>\alpha_{a, \min }$. In order to reduce the length of this section, the intercomparison results are listed for only three cases when the aerosol load condition was fulfilled for each instrument and each wavelength (Table IV), and the results are illustrated by plotting the normalized distance and the optical coefficient intercomparison in only one case (Figs. 2 and 3). The visualization of the color maps of $d_{a, b}(n, m)$ as a function of $z_{n}$ and $z_{m}$ gives qualitative information on how well the two compared systems agree in that altitude interval. The quantitative results are first presented in terms of aerosol backscatter and then aerosol extinction.

\section{A. Aerosol Backscatter}

The intercomparison between the Granada and Barcelona systems took place during Campaign 1. The results at $1064 \mathrm{~nm}$ on June 28, 2006 at 1856-1906 UTC and at $532 \mathrm{~nm}$ on June 28, 2006 at 1623-1633 UTC are shown in Fig. 2(a) and (b), respectively. In both maps of $d_{a, b}(n, m)$, the normalized distance is clearly well below 0.1 (dark gray) between the two heights $h_{\min }$ and $h_{\max }$. At $1064 \mathrm{~nm}$, the agreement very quickly deteriorates above $h_{\max }$ due to random noise since the molecular signals at that wavelength are very weak and the detectors are less sensitive, compared with those in the visible region. At both wavelengths, the comparison of the backscatter coefficient profiles is very good in the height interval selected, and all the relative deviations (see Table IV) are well below the maximum allowed values. In only one case at $532 \mathrm{~nm}$, corresponding to the day with maximum AOT, the absolute standard deviation exceeded $0.5 \times 10^{-6} \mathrm{~m}^{-1} \cdot \mathrm{sr}^{-1}$, which is the maximum allowed value. The height intervals oscillated between 1100 and $1500 \mathrm{~m}$; therefore, the requirement on the minimum height interval was not strictly fulfilled. However, in Campaign 1, high aerosol loads were observed in the ABL.

The Madrid and Barcelona systems at $532 \mathrm{~nm}$ were also intercompared in Campaign 1. The map of $d_{a, b}(n, m)$ on June 28, 2006 at 1448-1458 UTC in Fig. 2(c) shows low values of the normalized distance in the height interval selected. The color map jumps twice to a darker gray when increasing the minimum height $z_{n}$ of the distance computation range, i.e., at approximately 600 and $1400 \mathrm{~m}$, coinciding with two peaks observed on the backscatter profiles. The intercomparison of the backscatter coefficient is very good, even though the Madrid system's overlap factor seems to increase more slowly than expected: If compared with the Barcelona profile, the full overlap seems to be reached at $1250 \mathrm{~m}$, instead of the expected $400 \mathrm{~m}$ (see Table I). In the three cases listed in Table IV about the MAD-BAR intercomparison, all the absolute and relative values of both deviations stay well below the maximum allowed values. The height interval varies between 1200 and $1500 \mathrm{~m}$. As for the GRA-BAR intercomparison, the minimum height interval requirement is not fulfilled, but high aerosol loads were observed in the ABL, i.e., an AOT in the range of 0.14-0.32 at $532 \mathrm{~nm}$ during the campaign.

The Valencia system participated in Campaign 1, but as it was the first deployment of the instrument, some problems that could not be solved within the five days of the campaign occurred. The experiment was repeated in Campaign 2. As the Valencia system uses a very low energy laser $(4 \mu \mathrm{J}$ at $4.6-\mathrm{kHz}$ pulse repetition frequency), the intercompared profiles were integrated over $30 \mathrm{~min}$. In those conditions, the molecular signal could be detected up to $3000 \mathrm{~m}$ with the Valencia system. If started above $3000 \mathrm{~m}$, the inversion could suffer from large errors if it is initiated in a noisy cell or a nonaerosol-free region of the troposphere. As far as our analysis is concerned, this aspect did not limit our intercomparison since no aerosol layer was observed above $2800 \mathrm{~m}$ during Campaign 2. However, this limiting aspect of the Valencia system should be taken into account when the instrument is to be used for the observation of high-altitude $(>3000 \mathrm{~m}$ ) aerosol layers. In Fig. 2(d), the map of the normalized distance clearly shows the limitation of the system below $800 \mathrm{~m}$ due to the "afterpulse" effects and above $2500 \mathrm{~m}$ because of the low sensitivity of the system to molecular signals. The "afterpulse" is a detector noise induced from the firing of the laser [15], [16] that occurs when the emission and reception optical axes are not totally decoupled, i.e., when some optical components are common to the emission and the reception layouts. When the laser pulse is emitted, the detector saturates. The saturated signal is then corrected 

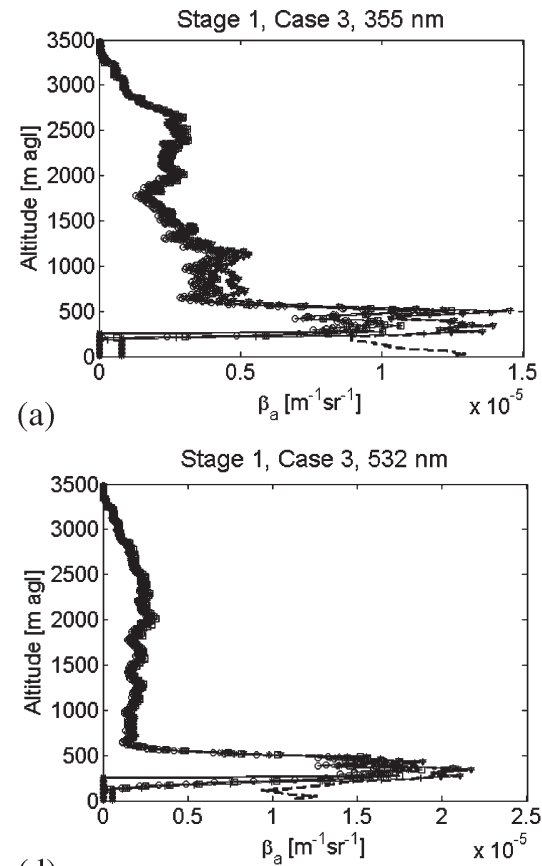

(d)
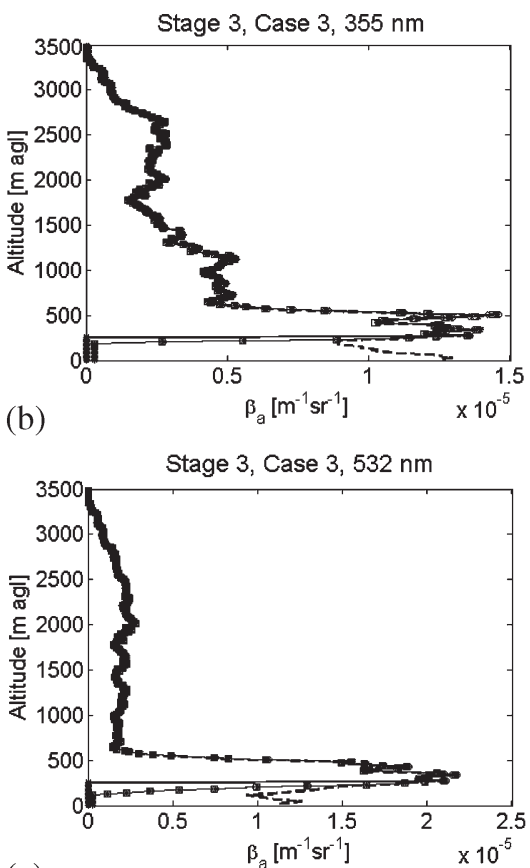

(e)

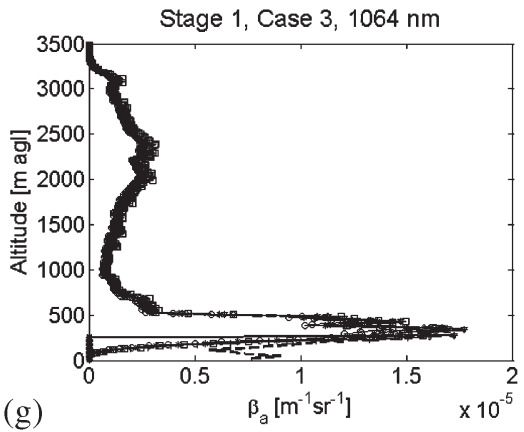

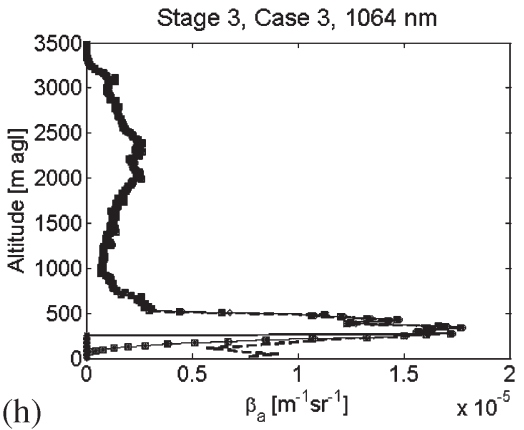
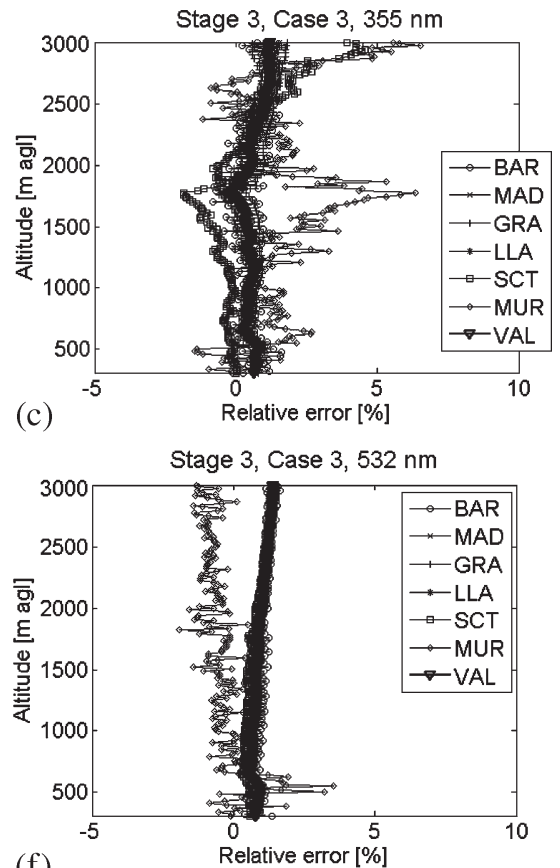

(f)

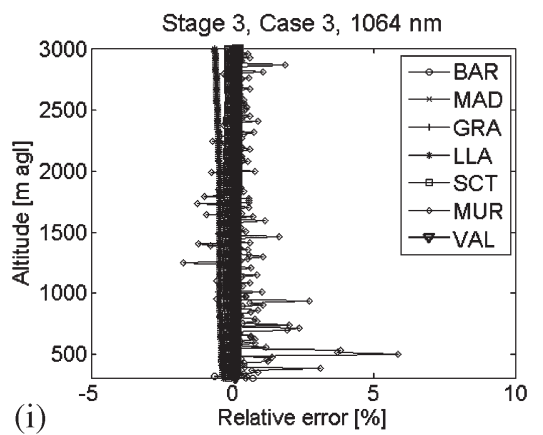

Fig. 4. Retrieved aerosol backscatter coefficient profiles at all three wavelengths, compared with the simulation input profiles of case 3 for (a), (d), and (g) stage 1 and (b), (e), and (h) stage 3. The exact profile is shown in dashed lines. (c), (f), and (i) Relative errors for case 3 and stage 3.

with a calibration profile. However, even after the correction has been made, the minimum height of confidence given by the manufacturer is about $800 \mathrm{~m}$. Between the two heights selected $h_{\min }=800 \mathrm{~m}$ and $h_{\max }=1800 \mathrm{~m}$, the backscatter coefficient profile compares very well with that of Barcelona. In the three cases listed in Table IV, all values are well below the maximum allowed values, except the relative value of the standard deviation on February 7, 2007 at 0852-0922 UTC. In that measurement, a very weak aerosol layer $\left(\beta_{a}<0.1 \times\right.$ $\left.10^{-6} \mathrm{~m}^{-1} \cdot \mathrm{sr}^{-1}\right)$ located above the ABL between 1200 and $1800 \mathrm{~m}$ was taken into account. The low sensitivity of the Valencia system may explain the bad agreement in terms of the absolute values. This case emphasizes the difficulties of that system to accurately retrieve weak aerosol optical coefficients at least with a relatively short (30 $\mathrm{min})$ integration time. Like in Campaign 1, the minimum height interval requirement was not fulfilled, but high aerosols loads were observed in the ABL, i.e., an AOT in the range of $0.11-0.39$ at $532 \mathrm{~nm}$ during the campaign.

Because the La Laguna system is not transportable, the Barcelona system was shipped to the Canary island of Tenerife during Campaign 3. The 1064-nm detector of the La Laguna system, which is a cooled photomultiplier tube with very poor sensitivity, had reached the end of its lifetime by the time of the campaign. Its replacement could not be made on time; therefore, the 1064-nm channel of the La Laguna could not be intercompared. The map of $d_{a, b}(n, m)$ on June 26, 2007 at 1605-1615 UTC shown in Fig. 2(e) shows a very low normalized distance up to the range of 2500-2800 m, which means a very good signal similarity between the La Laguna and Barcelona systems. Between $h_{\min }=500 \mathrm{~m}$ and $h_{\max }=$ $2500 \mathrm{~m}$, the backscatter profiles agree very well. The aerosol load during Campaign 3 was lower in terms of AOT $(<0.1$ at $532 \mathrm{~nm}$ during the campaign), compared with that of the two previous campaigns, but the aerosol layers were thicker. The height intervals vary between 1900 and $2000 \mathrm{~m}$ (see Table IV). All the absolute values of both deviations are well within the maximum allowed values. In turn, the relative values are quite high: Most of the time, they are higher than the maximum allowed values, because they reflect variations relative to a small magnitude $\left(\beta_{a}<0.3 \times 10^{-6} \mathrm{~m}^{-1} \cdot \mathrm{sr}^{-1}\right.$ between 1500 and $2500 \mathrm{~m}$ ).

The SCT system, which is usually dedicated to routine measurements within the Micro Pulse Lidar Network [17], [18], was also brought to La Laguna for the time of Campaign 3. Two points have to be noted: 1) The elastic wavelength of that 
system is $523 \mathrm{~nm}$, and no spectral correction was applied to compare with the 532-nm channel of the Barcelona system. 2) It is the only system to which an overlap factor correction was applied. The SCT system reaches its full overlap at a very high altitude $(1.5-2 \mathrm{~km})$, and the overlap correction appeared to be the only way for the system to participate in the intercomparison experiment. The map of the normalized distance shown in Fig. 2(f) is very similar to that from the La Laguna system [Fig. 2(e)]. The intercomparison of the backscatter profile shows a very good agreement between both systems, with small discrepancies observed around 500 and $1000 \mathrm{~m}$ at the top of the ABL. The minimum height interval requirement was fulfilled since the height interval varied between 2000 and $2700 \mathrm{~m}$ (see Table IV). All absolute deviations stayed well below the maximum allowed values, and all the relative values were below or very close to the maximum allowed values.

\section{B. Aerosol Extinction}

The aerosol extinction could be retrieved only in one case, i.e., on June 28, 2006 at 2101-2301 UTC. A second nocturnal Raman measurement was performed on the next day, but strong synchronous interferences prevented inversion of the Barcelona profile. The extinction profiles of Madrid and Barcelona are shown in Fig. 3, and the deviation values are given at the bottom of Table IV. $h_{\min }$ and $h_{\max }$ were set up to 900 and $2500 \mathrm{~m}$, respectively. Some artifacts such as the sudden extinction step at $2100 \mathrm{~m}$ observed on the Barcelona profile are purely algorithmic and are due to the partitioning of the profiles in successive ranges where a different fitting length (inversion resolution) is applied. In this particular case, $2100 \mathrm{~m}$ is precisely the height delimiting the second and third partitions. On the one hand, both profiles have a similar shape with two peaks at 1150 and $2000 \mathrm{~m}$ observed approximately at the same height on both profiles. On the other hand, their magnitudes are quite different, and in general, the retrieval of the extinction from the Madrid system seems to be underestimated, compared with that from the Barcelona system. However, the absolute deviations stay within the maximum allowed values and, in that way, validate the extinction intercomparison. In turn, the relative values are quite high, particularly the standard deviation, which reaches 59.6\%. In Matthias et al. [6], the largest relative values also occurred for the standard deviations. One of the main difficulties in accurately determining the extinction coefficient lies in the calculation of the derivative of the logarithm of the Raman signal, which was particularly noisy in the measurement presented here.

\section{BACKSCATTER ALGORITHM INTERCOMPARISON: METHODOLOGY AND RESULTS}

In order to assure the quality of backscatter algorithms used by each member of the network, an intercomparison exercise similar to that in [19] was performed. All groups (except Cartagena) inverted with their own algorithm the aerosol backscatter profiles at 355, 532, and $1064 \mathrm{~nm}$ from a set of profiles of simulated elastic lidar signals under two atmospheric conditions (cases) and three situations (stages). Both atmospheric conditions are fully described in [19] (cases 2 and 3 ).

1) In case 2 , realistic extinction profiles were simulated with height-independent but wavelength-dependent lidar ratios.

2) In case 3, realistic extinction profiles were also simulated with height-dependent but wavelength-independent lidar ratios.

Since the conditions in case 3 correspond to the most realistic atmospheric conditions, only the results from that case are presented in this paper. In all stages, the simulated signals and the standard atmosphere used were distributed along with the following:

Stage 1: no further information (real-life situation);

Stage 2: prescribed lidar ratio profile at all wavelengths;

Stage 3: prescribed lidar ratio profile and the reference value at the calibration height at all wavelengths.

The backscatter algorithm comparison presented here also demonstrated what Böckmann et al. [19] concluded: "The effect of the reference value was rather small." For that reason, only the results from stages 1 and 3 are presented next, with the difference between stages 2 and 3 being negligible.

Fig. 4 shows the retrieved aerosol backscatter coefficient profiles from all groups for stages 1 and 3 at all wavelengths. In the layer of lower aerosol load $(0.6-3.3 \mathrm{~km})$, the difference between stages 1 and 3 is barely visible at 532 and $1064 \mathrm{~nm}$, whereas it is clearly visible at $355 \mathrm{~nm}$. This emphasizes that, in low aerosol loading, the accuracy of the retrieved backscatter coefficient at 532 and $1064 \mathrm{~nm}$ does not strongly depend on the knowledge of the lidar ratio used in the inversion. Fig. 4(c), (f), and (i) represents the relative errors for stage 3 at 355, 532, and $1064 \mathrm{~nm}$, respectively, calculated using [19, eq. (7)]. In detail, the mean relative errors calculated over the range of 0.3075-3.0075 km and over all groups for wavelengths of 355, 532, and $1064 \mathrm{~nm}$ are approximately $0.9 \%, 0.9 \%$, and $0.22 \%$, respectively. For stages 1 and 2, the respective mean relative errors were approximately $9.7 \%, 5.6 \%$, and $4.9 \%$, and $0.9 \%, 1 \%$, and $0.22 \%$, respectively. As expected, the differences between stages 2 and 3 are very small $(<0.1 \%)$. In general, the errors for case 3 are somewhat larger than that for case 2 (not shown here), mainly because the lidar ratio is height dependent in case 3 . Note also that, below the full overlap height $(250 \mathrm{~m})$, none of the algorithms is able to correctly retrieve the aerosol backscatter. In the range of $3.0225-15.0675 \mathrm{~km}$, the mean absolute error for all groups is smaller than $1 \times 10^{-5} \mathrm{~km}^{-1}$. $\mathrm{sr}^{-1}$, indicating that all the algorithms retrieved the molecular profiles relatively well.

\section{CONCLUSION}

A nucleus of eight lidar groups was recently created the Spanish lidar network. In the long run, one of the main objectives of this small network is to be able to perform coordinated reliable measurements of the aerosol vertical distribution in terms of backscatter and extinction coefficients. Since the systems present many differences at the hardware level, a system intercomparison experiment was carried out in 
the period 2006-2007 between six of the systems in order to gain enough confidence to rely on the signals provided by each system. Additionally, a backscatter algorithm intercomparison was performed.

Three intercomparison campaigns were carried out. Five systems were compared with the Barcelona quality-assured lidar. Four of them met the quality assurance criterion from the beginning. In one case, a new campaign had to be organized after the system was better controlled by the owner group, and the system finally met the quality assurance criterion. The meteorological conditions met during the campaigns restricted intercomparisons to the height range of 500-3500 m, i.e., in the ABL and just above it, since no lofted aerosol layers were found in the free troposphere. In high aerosol loads, all absolute deviations (except in one case) of the backscatter coefficient were well within the limit of $0.5 \times 10^{-6} \mathrm{~m}^{-1} \cdot \mathrm{sr}^{-1}$, and all the mean deviations were smaller than $0.26 \times 10^{-6} \mathrm{~m}^{-1} \cdot \mathrm{sr}^{-1}$. The relative deviations were also usually within the maximum allowed value fixed by EARLINET, and in general, the standard deviation presented higher percentages, compared with the mean deviation. For the same instrument, the absolute values are smaller, and the relative values are higher at $1064 \mathrm{~nm}$ than at $532 \mathrm{~nm}$, which was a predictable result since backscatter coefficients are smaller and noise is usually higher at $1064 \mathrm{~nm}$ than at $532 \mathrm{~nm}$. In low aerosol loads, all absolute deviations of the backscatter coefficient stay well within the limit of $0.5 \times 10^{-6} \mathrm{~m}^{-1} \cdot \mathrm{sr}^{-1}$, and a significant number of relative values exceeded the relative limits, which was also a predictable result since the backscatter magnitudes are smaller as a whole.

In one case, the extinction coefficient at $532 \mathrm{~nm}$ was also compared. Even though the profiles retrieved were similar in shape, the magnitudes were quite different. The absolute deviations stay below the limit fixed by EARLINET, whereas the relative values were approximately twice larger than the maximum allowed values. The Raman signals, which were particularly noisy on the night of the measurements, resulted in retrieved extinction coefficients with large error bars, hence the difference between both profiles.

Although all intercomparisons satisfactorily ended, the field campaigns showed the importance of having each group know and control their system at the hardware level (detector saturation, overlap factor, electronic interferences, temperature instability, etc.) and estimating how the preprocessing (background calculation, afterpulse correction, smoothing techniques, etc.) affects the resulting inversions. One major concern once a subset of instruments has been intercompared is the question of the maintenance of the quality-assured signals. In that sense, satellite-borne lidars could be a key instrument as, once validated, they could play the role of the reference instrument.

The intercomparison at the software level, i.e., here, in terms of backscatter algorithm, was very satisfactory: When all inputs were given, the relative error was less than $2 \%$ for all groups and all wavelengths. The average over all groups is less than $0.9 \%$ for all wavelengths. These results demonstrate that all algorithms work well and can reproduce the profiles of the two atmospheric conditions that were simulated if all input parameters are known. The exercise showed that the knowledge of the lidar ratio was the critical factor for the algorithms to get closer to the solution, whereas the knowledge of the reference value at the calibration height had almost a negligible effect on the retrieved backscatter.

\section{REFERENCES}

[1] H. J. Zwally, B. Schutz, W. Abdalati, J. Abshire, C. Bentley, A. Brenner, J. Bufton, J. Dezio, D. Hancock, D. Harding, T. Herring, B. Minster, K. Quinn, S. Palm, J. Spinhirne, and R. Tomas, "ICESat's laser measurements of polar ice, atmosphere, ocean, and land," J. Geodyn., vol. 34, no. 3/4, pp. 405-445, Oct./Nov. 2002.

[2] D. Winker, J. Pelon, and M. McCormick, "Initial results from CALIPSO," in Proc. 23rd Int. Laser Radar Conf., C. Nagasawa and N. Sugimoto, Eds., 2006, vol. 2, pp. 991-994.

[3] D. Winker, W. Hunt, and M. McGill, "Initial performance assessment of CALIOP," Geophys. Res. Lett., vol. 34, no. 19, p. L19 803, 2007. DOI:10.1029/2007GL030135.

[4] J. Bösenberg, A. Ansmann, J. M. Baldasano, D. Balis, C. Böckmann, B. Calpini, A. Chaikovsky, P. Flamant, A. Hågård, V. Mitev, A. Papayannis, J. Pelon, D. Resendes, J. Schneider, N. Spinelli, T. Trickl, G. Vaughan, G. Visconti, and M. Wiegner, "EARLINET: A European aerosol research lidar network," in Advances in Laser Remote Sensing of the Atmosphere, A. Dabas, C. Loth, and J. Pelon, Eds. Palaiseau, France: Edition Ecole Polytechnique, 2001, pp. 155-158.

[5] G. Pappalardo, J. Bösenberg, A. Amodeo, A. Ansmann, A. Apituley, L. Alados Arboledas, D. Balis, C. Böckmann, A. Chaikovsky, A. Comeron, V. Freudenthaler, G. Hansen, V. Mitev, D. Nicolae, A. Papayannis, M. R. Perrone, A. Pietruczuk, M. Pujadas, J.-P. Putaud, F. Ravetta, V. Rizi, V. Simeonov, N. Spinelli, D. Stoyanov, T. Trickl, and M. Wiegner, "EARLINET-ASOS: European aerosol research lidar network-advanced sustainable observation system," in Proc. Amer. Meteorol. Soc. Annu. Meeting, San Antonio, TX, Jan. 2007.

[6] V. Matthias, J. Bösenberg, V. Freudenthaler, A. Amodeo, D. Balis, A. Chaikovsky, G. Chourdakis, A. Comeron, A. Delaval, F. De Tomasi, R. Eximann, A. Hågård, L. Komguem, S. Kreipl, R. Matthey, I. Mattis, V. Rizi, J. A. Rodríguez, V. Simeonov, and X. Wang, "Aerosol lidar intercomparison in the framework of the EARLINET project-Part 1: Instruments," Appl. Opt., vol. 43, no. 4, pp. 961-976, Feb. 2004.

[7] J. D. Klett, "Lidar inversion with variable backscatter/extinction ratios," Appl. Opt., vol. 24, no. 11, pp. 1638-1643, Jun. 1985.

[8] F. G. Fernald, "Analysis of atmospheric lidar observations: Some comments," Appl. Opt., vol. 23, no. 5, pp. 652-653, Mar. 1984.

[9] Y. Sasano and H. Nakane, "Significance of the extinction/backscatter ratio and the boundary value term in the solution for the two-component lidar equation," Appl. Opt., vol. 23, no. 1, pp. 11-13, Jan. 1984.

[10] B. A. Bodhaine, N. B. Wood, E. G. Dutton, and J. R. Slusser, "On Rayleigh optical depth calculations," J. Atmos. Ocean. Technol., vol. 16, no. 11 , pp. 1854-1861, Nov. 1999.

[11] A. Ansmann, U. Wandinger, M. Riebesell, C. Weitcamp, and W. Michaelis, "Independent measurement of extinction and backscatter profiles in cirrus clouds by using a combined Raman elastic-backscatter lider," Appl. Opt., vol. 31, no. 33, pp. 7113-7131, Nov. 1992.

[12] M. Sicard, F. Molero, J. L. Guerrero-Rascado, R. Pedrós, M. N. Md Reba, M. Pujadas, L. Alados-Arboledas, J. A. Martínez, F. Rocadenbosch, E. Gregorio, D. Kumar, S. Tomás, and A. Comerón, "Intercomparison of Spanish advanced lidars in the framework of EARLINET," in Proc. IGARSS, 2007, pp. 2763-2766.

[13] J. A. Martínez-Lozano, L. Alados-Arboledas, B. de la Morena, V. Estellés, F. J. Exposito, J. Pey, M. Sicard, and M. Sorribas, "Intercomparison of instrumentation for atmospheric aerosol measurements: DAMOCLES campaign," in Proc. Eur. Aerosol Conf., Salzburg, Austria, Sep. 9-14, 2007. Abstract T13A230.

[14] B. Holben, T. F. Eck, I. Slutsker, D. Tanré, J. P. Buis, A. Setzer, E. Vermote, J. A. Reagan, Y. J. Kaufman, T. Nakajima, F. Lavenu, I. Jankowiak, and A. Smirnov, "AERONET-A federated instrument network and data archive for aerosol characterization," Remote Sens. Environ., vol. 66, no. 1, pp. 1-16, Oct. 1998.

[15] J. R. Campbell, D. L. Hlavka, E. J. Welton, C. J. Flynn, D. D. Turner, J. D. Spinhirne, V. S. Scott, and I. H. Hwang, "Full-time, eye-safe cloud and aerosol lidar observation at atmospheric radiation measurement program sites: Instruments and data processing," J. Atmos. Ocean. Technol., vol. 19, no. 4, pp. 431-442, Apr. 2002.

[16] E. J. Welton and J. R. Campbell, "Micropulse lidar signals: Uncertainty analysis," J. Atmos. Ocean. Technol., vol. 19, no. 12, pp. 2089-2094, Dec. 2002. 
[17] J. M. Spinhirne, "Micro pulse lidar," IEEE Trans. Geosci. Remote Sens., vol. 31, no. 1, pp. 48-55, Jan. 1993.

[18] E. J. Welton, J. R. Campbell, J. D. Spinhirne, and V. S. Scott, "Global monitoring of clouds and aerosols using a network of micro-pulse lidar systems," in Proc. SPIE - Lidar Remote Sensing for Industry and Environmental Monitoring, U. N. Singh, T. Itabe, and N. Sugimoto, Eds., 2001, vol. 4153, pp. 151-158.

[19] C. Böckmann, U. Wandinger, A. Ansmann, J. Bösenberg, V. Amiridis, A. Boselli, A. Delaval, F. De Tomasi, M. Frioud, I. Videnov Grigorov, A. Hågård, M. Horvat, M. Iarlori, L. Komguem, S. Kreipl, G. Larchevêque, V. Matthias, A. Papayannis, G. Pappalardo, F. Rocadenbosch, J. A. Rodrigues, J. Schneider, V. Shcherbakov, and M. Wiegner, "Aerosol lidar intercomparison in the framework of the EARLINET project—Part 2: Aerosol backscatter Algorithms," Appl. Opt., vol. 43, no. 4, pp. 977-989, Feb. 2004.

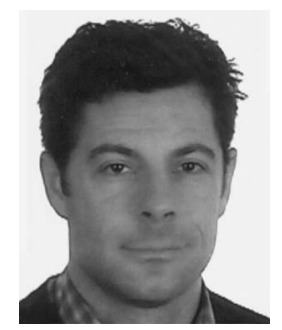

Michaël Sicard received the M.S. and Ph.D. degrees in physical methods for remote sensing from the Service d'Aéronomie, Institut Pierre-Simon-Laplace, Paris, France, in 1995 and 2000, respectively.

$\mathrm{He}$ is currently an Associate Professor with the Remote Sensing Laboratory (RSLab), Department of Signal Theory and Communications, and the Institut d'Estudis Espacials de Catalunya, Centre de Recerca de l'Aeronàutica i de l'Espai, Universitat Politècnica de Catalunya, Barcelona, Spain. He is also the Coordinator of the Spanish/Portuguese lidar network. His research interests are twofold: 1) on a technical point of view, the development of lidar techniques and instruments in all their aspects for aerosol observations and 2) the study of aerosols, which includes aerosol optical and microphysical characterization by means of data fusion, aerosol transport, atmospheric boundary layer study, and modeling.

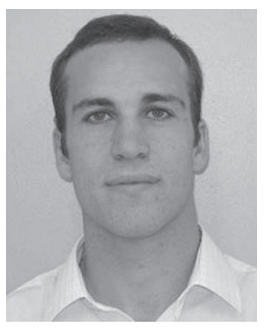

Francisco Molero received the Ph.D. degree in physics from the Universidad Autonoma de Madrid, Madrid, Spain, in 1998 and the M.Sc. degree in optoelectronic and laser devices from Heriot-Watt University, Edinburgh, U.K., in 1996.

Since 1999, he has been a Research Scientist with the Atmospheric Pollution Group, Centro de Investigaciones Energéticas, Medioambientales y Tecnológicas (CIEMAT), Madrid. His research interests include remote sensing of pollutants and aerosols, and lidar system design and implementation.

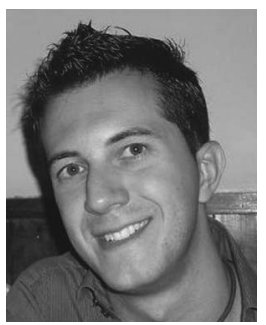

Juan Luis Guerrero-Rascado received the B.Sc. degree in physics, the M.Sc. degree in methods and advanced techniques in physics, the M.Sc. degree in geophysics and meteorology, and the Ph.D. degree in physics from the University of Granada, Granada, Spain, in 2004, 2006, 2007, and 2008, respectively.

$\mathrm{He}$ is currently with the Atmospheric Physics Group, Centro Andaluz de Medio Ambiente (CEAMA), University of Granada. His research interests include the different aspects of atmospheric aerosol, with special interest on their optical properties retrieved by means of active (lidar) and passive (photometry) remote sensing.

Dr. Guerrero-Rascado has been a member of the Association for Aerosol Research (GAef) since 2004.

Roberto Pedrós, photograph and biography not available at the time of publication.

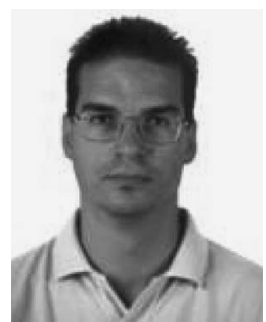

Francisco Javier Expósito received the M.Sc. degree in environmental management, with specialization in environmental assessment, and the Ph.D. degree in physics from the University of La Laguna, La Laguna, Spain, in 1997 and 1999, respectively.

Since 1990, he has been with the Department of Fundamental Physics, University of La Laguna, where he is currently an Associated Professor and a member of the Grupo de Observacion de la Tierra y la Atmosfera (GOTA). His research interests include aerosols, solar radiation, and aerosol radiative forcing using remote-sensing techniques (e.g., satellites, photometers, and LIDARs).

Carmen Córdoba-Jabonero, photograph and biography not available at the time of publication.

José Miguel Bolarín, photograph and biography not available at the time of publication.

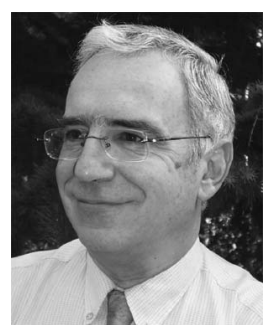

Adolfo Comerón (SM'76-M'82) received the M.S. degree in telecommunication engineering from the Telecommunication Engineering School of Barcelona, Barcelona, Spain, in 1976 and the DEA and Dr.Eng. (Ph.D.) degrees from Paris-XI University, Orsay, France, in 1977 and 1980, respectively.

He is currently a Professor with the RSLab, Department of Signal Theory and Communications, Technical University of Catalonia, Barcelona. His research interests include the study of nonlinear devices at IR wavelengths and the development of microwave and millimeter-wave receivers for satellite communication systems, focusing on lidar remote-sensing and free-space optical communications.

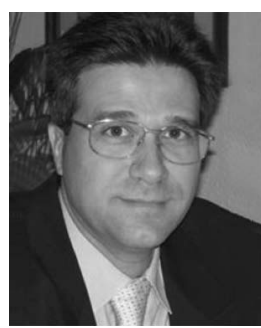

Francesc Rocadenbosch received the Engineer and $\mathrm{Ph} . \mathrm{D}$. degrees in telecommunication engineering from the Technical University of Catalonia (UPC), Barcelona, Spain, in 1991 and 1996, respectively, and the M.B.A. degree from the University of Barcelona, Barcelona, in 2001.

During 1991-1992, he was with the University of Las Palmas de Gran Canaria, working on microwave systems. In 1993, he joined the Electromagnetics and Photonics Engineering (EEF) Group, Department of Signal Theory and Communications (TSC), UPC, where he has been an Associate Professor since 1997. He is a joint representative of the Remote Sensing Laboratory (RSLab), Department of Signal Theory and Communications, and the Institut d'Estudis Espacials de Catalunya, Centre de Recerca de l'Aeronàutica i de l'Espai, UPC, where he is currently steering the development of the UPC multispectral elastic-Raman lidar. He is a Reviewer of well-known international journals, such as Applied Optics, Optics Letters, and Optical Engineering. His research interests include LIDAR (laser radar) remote sensing, related system design, and signal processing.

Dr. Rocadenbosch is a Reviewer of the IEEE TRANSACTIONS ON SIGNAL PRocessing. He, along with the rest of the lidar team members, was the recipient of the Salvà i Campillo Award of the Catalan Association of Telecommunication Engineers for the Best Research Project in 1998. He was also the recipient of the Telecommunications National Award in 2003 as a member of the EEF Group, TSC Department.

Manuel Pujadas received the Ph.D. degree in physics from the Universidad Complutense de Madrid, Madrid, Spain, in 2002.

He is currently with the Department of the Environment, Centro de Investigaciones Energéticas, Medioambientales y Tecnológicas (CIEMAT), Madrid. He leads different R\&D projects and closely collaborates with the Spanish environmental administration. His research interests include atmospheric pollution and remote sensing of air pollutants. 


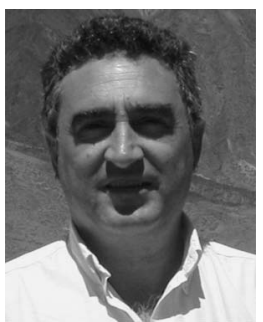

Lucas Alados-Arboledas received the M.Sc. and $\mathrm{Ph} . \mathrm{D}$. degrees in physics from the University of Granada, Granada, Spain, in 1983 and 1987, respectively.

$\mathrm{He}$ is the Principal Investigator of atmospheric physics and a Professor of applied physics with the Atmospheric Physics Group, Centro Andaluz de Medio Ambiente (CEAMA), University of Granada. His research interests include the different aspects of the Earth energy balance, paying special attention to the radiative processes and the use of active and passive remote-sensing tools.

Jose Antonio Martínez-Lozano, photograph and biography not available at the time of publication.

Juan Pedro Díaz, photograph and biography not available at the time of publication.

Manuel Gil, photograph and biography not available at the time of publication.

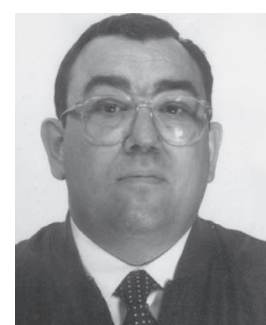

Alberto Requena is currently a Full Professor with the Department of Chemistry-Physics, Facultad de Química, Universidad de Murcia, Murcia, Spain, working on quantum theoretical treatment of energy levels for several molecular systems, some of which are involved in the environmental aspects. He is the author of more than 200 papers related on these topics. He is the author of several books, such as $E s$ pectroscopia (Pearson Education, 2004), Problemas de Química Física (Pearson Education, 2006), and Irradiación solar, Ozono y Contaminación urbana en los municipios de la Región de Murcia (Consejere Industria y Medio Ambiente, 2005). His research interests are the theoretical treatment of the interaction between radiation and matter including laser in chemistry, and applications to environmental studies.

Prof. Requena is a member of the Real Sociedad Española de Física and the Real Sociedad Española de Química, and a Referee of the Principal Publicattions on Speciallity. He was the recipient of the Extraordinary Price of Ph.D. and an award from the Intergovernmental Bureau for Informatics in the Spanish Language area for his work on the application of informatics on education.

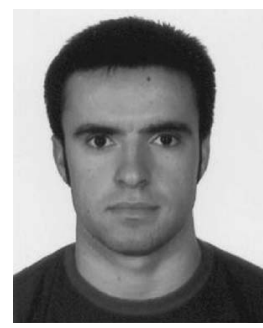

and sun photometers.
Francisco Navas-Guzmán received the B.S. degree in physics and the M.S. degree in geophysics and meteorology from the University of Granada, Granada, Spain, in 2006 and 2007, respectively. He is currently working toward the Ph.D. degree in atmospheric science in the Atmospheric Physics Group, Centro Andaluz de Medio Ambiente (CEAMA), University of Granada.

His research interests include the study of atmospheric aerosols using passive and active remotesensing techniques, with particular reference to lidars
José Maria Moreno, photograph and biography not available at the time of publication. 